\title{
Nilai Pendidikan Agama Hindu Dalam Lontar Siwa Sasana
}

\author{
Ida Bagus Putu Eka Suadnyana1, I Putu Ariyasa Darmawan² \\ 12STAHN Mpu Kuturan Singaraja \\ 1.
}

DOI : $10.37329 /$ cetta.v3i2.460

\begin{tabular}{l}
\hline Keywords: \\
\hline Values; Shiva \\
Sasana; Hindu \\
Religious \\
Education \\
\hline
\end{tabular}

\begin{abstract}
Hinduism in addition to giving teachings also guides its people to achieve happiness and harmonize their lives physically and spiritually. Efforts to maintain the preservation of Religion can be done through strengthening education in the field of religion. For people in Bali this is the basic capital as a mental and spiritual driving force and is a guide, guide and impetus in humans to achieve $a$ better and perfect quality of life. The teachings of Hinduism are based on the Vedic scriptures, but also in secondary books, one of which is the ancient manuscripts in the form of Lontar. Dealing with this, the author intends to examine in depth in terms of the value of Hindu religious education for a lontar, namely lontar "Shiva Sasana" which is a religious literary work that is currently only in demand by a small portion of the community or less attention from the younger generation of Hindus. Theories used to solve research problems are convergence theory and value theory. This research is in the form of a qualitative design with data collected with literature study techniques and interpretive methods. After the data collected the data were analyzed with descriptive analysis techniques. The teachings contained in the Lontar Shiva Sasana based on the writer's findings include the teachings of Shivaism and the teachings of the Trikaya Parisudha and the values contained in the Lontar Shiva Sasana include the ethical values and devotional values.
\end{abstract}

\begin{tabular}{|c|c|}
\hline Kata Kunci: & Abstrak \\
\hline $\begin{array}{l}\text { Nilai-Nilai; Siwa } \\
\text { Sasana; } \\
\text { Pendidikan } \\
\text { Agama Hindu }\end{array}$ & $\begin{array}{l}\text { Agama Hindu selain memberikan ajaran, juga menuntun } \\
\text { umatnya untuk mencapai kebahagiaan dan menyelaraskan } \\
\text { hidupnya secara lahir batin. Usaha-usaha untuk menjaga } \\
\text { pelestarian Agama dapat dilakukan melalui pemantapan }\end{array}$ \\
\hline & $\begin{array}{l}\text { pendidikan di bidang agama. Bagi masyarakat di Bali hal ini } \\
\text { merupakan modal dasar sebagai tenaga penggerak mental } \\
\text { spiritual dan merupakan pedoman, pembimbing serta } \\
\text { pendorong dalam diri manusia untuk mencapai kualitas } \\
\text { hidup yang lebih baik dan sempurna. Ajaran Agama Hindu } \\
\text { bersumber pada kitab suci Weda, namun juga terdapat dalam }\end{array}$ \\
\hline
\end{tabular}




kitab-kitab sekunder yaitu naskah-naskah kuno salah satunya
berupa Lontar. Berkenan dengan hal tersebut, penulis
bermaksud mengkaji secara mendalam dari segi nilai
pendidikan Agama Hindu terhadap sebuah lontar, yaitu lontar
"Siwa Sasana" yang merupakan karya sastra keagamaan yang
saat ini hanya diminati oleh sebagian kecil masyarakat atau
kurang mendapat perhatian dari generasi muda Hindu. Teori
yang digunakan untuk memecahkan masalah penelitian
adalah teori konvergensi dan teori nilai. Penelitian ini
berbentuk rancangan kualitatif dengan data dikumpulkan
dengan teknik studi pustaka dan metode interpretatif. Setelah
data terkumpul data dianalisis dengan teknik deskriptif
analisis. Ajaran-ajaran yang terkandung dalam Lontar Siwa
Sasana berdasarkan temuan penulis meliputi ajaran Siwaisme
dan ajaran Trikaya Parisudha dan nilai yang terkandung dalam
Lontar Siwa Sasana meliputi nilai etika dan nilai bhakti.

\section{Pendahuluan}

Pendidikan Agama Hindu memiliki peran yang sangat penting dalam Negara Kesatuan Republik Indonesia. Agama dapat meningkatkan Sradha umatnya dan dapat juga meningkatkan perilaku yang luhur, sopan, santun, meningkatkan kesejahteraan dalam menjalankan tugas atau kewajiban baik dirinya pribadi maupun kepentingan masyarakat. Negara Indonesia memberikan kebebasan kepada masing-masing penduduk untuk memeluk Agama dan beribadah menurut kepercayaannya. Pemerintah menyadari adanya perbedaan di dalam menjalankan, melaksanakan dan menghayati ajaran agama, namun secara prinsip setiap umat mempunyai keyakinan atau kepercayaan terhadap Tuhan Yang Maha Esa (Suadnyana, 2020).

Agama Hindu sebagai agama yang sanatana dharma (sempurna dan abadi) yang memilki 3 kerangka dasar yang meliputi tattwa (filsafat), susila (etika), upacara (ritual). Ketiga unsur ini merupakan satu kesatuan yang harus dipahami dan dilaksanakan oleh umat Hindu secara integral dan seimbang. Untuk mengantisipasi adanya kecenderungan terjadinya pergeseran nilai dan norma-norma sosial kehidupan umat manusia, sebagai akibat dari adanya faktor-faktor negatif industrialisasi dan kemajuan teknologi, maka diperlukan adanya wadah dan pedoman. Teknologi bukanlah untuk dicemaskan, apalagi untuk dimusuhi, melainkan moral-moral manusialah yang perlu dibina (Suadnyana, 2020)

Usaha-usaha untuk menjaga pelestarian Agama dapat dilakukan dengan yang paling efektif adalah melalui pemantapan pendidikan di bidang agama (Yuniastuti \& 
Suadnyana, 2019). Ajaran Agama Hindu bersumber pada kitab suci Weda, namun juga terdapat dalam kitab-kitab sekunder yaitu naskah-naskah kuno salah satunya berupa Lontar. Naskah-naskah kuno yang berupa Lontar tersebut merupakan warisan nenek moyang umat Hindu yang tak ternilai harganya, karena di dalam naskah-naskah tersebut terkandung berbagai tuntunan yang berhubungan dengan ajaran moral, etika, acara agama dan lain-lain. Berkenaan dengan hal tersebut, penulis bermaksud mengkaji secara mendalam dari segi pendidikan Agama Hindu terhadap sebuah lontar, yaitu lontar "Siwa Sasana" yang merupakan karya sastra keagamaan yang saat ini hanya diminati oleh sebagian kecil masyarakat atau kurang mendapat perhatian dari generasi muda Hindu. Kajian terhadap Lontar Siwa Sasana ini untuk tambahan informasi ataupun diharapkan dapat merekayasa literature sasana para Pandita di Bali khususnya dan di Indonesia umumnya. Seperti ditunjukan oleh namanya, Siwa Sasana, maka sasana ini adalah untuk para pandita Siwa.

Bila dikaitkan dengan kondisi masyarakat dewasa ini, yang nampaknya semakin jauh dari apa yang diharapkan oleh tujuan pendidikan secara umum, serta harapan dari nilai-nilai yang terdapat dalam agama Hindu, maka usaha untuk mendalami dan menyebarkan ajaran-ajaran luhur dalam berbagai naskah kuno (lontar) mutlak dilakukan. Nilai-nilai Pendidikan Agama Hindu yang terdapat dalam Lontar Siwa Sasana tidak hanya untuk diketahui, dipahami, dihayati dan diamalkan oleh seorang Pandita saja namun hendaknya juga diketahui, dipahami, dihayati dan diamalkan oleh umat Hindu yang ada di Dunia ini. Selama ini belum ada penelitian khusus mengenai Nilai Pendidikan Agama Hindu yang terdapat dalam Lontar Siwa Sasana, sehingga penulisan ini dipandang perlu untuk dapat membahas secara lebih mendalam mengenai nilai-nilai tersebut sehingga hasilnya nanti dapat digunakan dan dimanfaatkan untuk kepentingan umat. Selain itu hal menarik lainnya yang terdapat dalam Lontar ini adalah ajaran-ajaran luhur mengenai sasana seorang Pandita dimana ajaran luhur ini mengajarkan tentang bagaimana menjadi seorang pandita sesuai dengan konsep Agama Hindu.

\section{Metode}

Penelitian ini merupakan penelitian lapangan yang dirancang untuk mengetahui Nilai Pendidikan Agama Hindu dalam Lontar Siwa Sasana. Pendekatan yang digunakan adalah pendekatan kualitatif. Metode kualitatif dapat digunakan untuk 
mengungkap dan memahami sesuatu dibalik fenomena yang sedikitpun belum diketahui (Semiawan, 2010). Metode ini dugunakan untuk mendapatkan wawasan tentang sesuatu yang baru dan sedikit diketahui (Kaelan, 2005). Berdasarkan pengertian tersebut di atas maka dalam penelitian ini pengkajian terhadap Lontar Siwa Sasana sebagai sasaran (objek) penelitian dilakukan dengan menganalisis karya tersebut mengenai nilai pendidikan Agama Hindu yang terdapat di dalamnya secara mendalam sehingga diperoleh hasil yang memadai. Sehubungan dengan penelitian ini maka metode kualitatif digunakan untuk menjelaskan informasi yang ada secara lengkap dan cermat. Dalam hal ini peneliti terlebih dahulu melakukan pengkajian, penjajakan, pengamatan terhadap beberapa sumber buku seperti, buku pendidikan Agama Hindu, Lontar Siwa Sasana, Alih Aksara Lontar Siwa Sasana dan buku Siwa Sasana. Adapun sumber data pada karya tulis ilmiah ini yaitu sumber data primer dari Lontar Siwa Sasana dan sumber data sekunder adalah referensi dari buku-buku, skripsiskripsi, dokumen-dokumen yang berkaitan dengan tujuan penelitian

Kecermatan dalam memilih dan menyusun teknik dan alat-alat pengumpul data ini sangat berpengaruh terhadap objektivitas hasil penelitian (Kaelan, 2005). Dalam metode pengumpulan data penulis menggunakan beberapa metode yaitu Studi kepustakaan, Metode interpretatif. Oleh karena dalam penelitian ini berwujud katakata, kalimat dan paragraph yang dinyatakan dalam bentuk narasi yang bersifat deskritif sebagai ciri khas penelitian kualitatif, maka dilakukan analisis kualitatif dengan tehnik deskritif analisis, deskritif dilakukan dengan tiga jalur kegiatan yang merupakan satu kesatuan yaitu : Reduksi data, Penyajian data, Penarikan kesimpulan atau verifikasi (Moleong, 1991). Reduksi data berlangsung terus-menerus selama proyek yang berorientasi penelitian kualitatif berlangsung. Bila dikaitkan dengan penelitian ini reduksi data diterapkan pada saat mengnalisis Lontar Siwa Sasana, lewat objek dimana setiap bagian Lontar dibuatkan penyederhanaan data lewat catatancatatan kecil, sehingga nantinya diperoleh data yang lebih akurat.

\section{Hasil dan Pembahasan}

Lontar Siwa Sasana yang dijadikan bahan pengkajian dalam penelitian ini merupakan koleksi milik Pusat Dokumentasi Kebudayaan Propinsi Bali yang berkode S/III/12/DOKBUD. Lontar Siwa Sasana ini berasal dari Tista, Abang, Kabupaten Karangasem dan memiliki panjang $40 \mathrm{~cm}$ dan lebar 3,5 cm dan berjumlah 16 lembar. 
Lontar Siwa Sasana yang ada di Pusat Dokumentasi Provinsi Bali keadaan fisiknya cukup baik, ini dapat dilihat dari bentuk lontar yang masih untuh dan terawat serta tulisan yang masih nampak jelas. Selain teks Lontar asli, bahan pengkajian dalam penelitian ini juga menggunakan teks alih aksara dari Lontar Siwa Sasana, teks ini juga merupakan koleksi dari Pusat Dokumentasi Kebudayaan Provinsi Bali dengan kode SES.30 4-6. Teks alih aksara Lontar Siwa Sasana ini merupakan turunan Lontar dari Gedong Kirtya Kabupaten Buleleng, dengan nomor IIb. 616/4 dari pecak turunan lontar druwen Padanda Nyoman Sebali Saking Pegesangan Lombok. Alih Aksara Lontar Siwa Sasana diterjemahkan dari bentuk lontar menjadi bentuk buku, dari aksara Bali menjadi aksara latin dan dari bahasa Jawa Kuno menjadi bahasa Indonesia yang ditulis dalam buku yang berjudul Siwa Sasana.

Begitu pentingnya ajaran yang terdapat di dalamnya, Lontar Siwa Sasana yang pada mulanya berbentuk lontar ini diterjemahkan dan dialih aksarakan dalam bentuk buku oleh sebuah tim penerjemah. Jumlah halaman dalam buku ini adalah sebanyak 12 halaman. Adapun penyusun dari alih aksara Lontar Siwa Sasana ini adalah I Made Wijana pada tanggal 8 juli 1976 dan diketik kembali oleh I Ketut Dana pada tanggal 27 juni 1988.

\section{Ajaran-Ajaran Yang Terkandung Dalam Lontar Siwa Sasana}

Seperti ditunjukan oleh namanya, Siwa Sasana, maka sasana ini adalah untuk para pandita Saiwa. Karena di dalamnya ada menyebutkan bahwa sasana ini untuk pandita Saiva di Jawa, maka dapat ditarik kesimpulan bahwa lontar ini ditulis di Jawa. Bhatara Siwa dipuja oleh umat Hindu Indonesia. Ia dipuja sebagai Trimurti yaitu : Brahma, Wisnu dan Iswara, sebagai Panca Brahma yaitu: Sadya/Sadyajata, Bamadewa, Tatpurusa, Aghora dan Isana sebagai Dewata Nawa Sangha yaitu; Mahesvara, Brahma, Rudra, Mahadewa, Sangkara, Wisnu, Sambhu dan Siwa.

Ajaran Ketuhanan seperti ini direalisasikan dalam membangun merajan, sanggah, pura, dalam banten, dalam puja dan sebagainya. Di dalam Siwa Sasana disebutkan adanya "paksa-paksa (sekte)"- Saiwa yaitu Saiwa Siddhanta, Waisnawa, Pasupata, Lepaka, Canaka, Ratnahara dan Sambhu. Diantara nama sekte-sekte itu yang masih sampai sekarang ialah Saiwa Siddhanta untuk menamakan ajaran agama Hindu Indonesia. Bila diamati ternyata lainlah Saiwa Siddhanta Indonesia dengan Saiwa Siddhanta di India. Saiwa Siddhanta Indonesia merupakan kristalisasi dari berbagai ajaran agama Hindu khususnya dari kitab-kitab Purana. Sehubungan dengan itu maka 
Saiva Indonesia kadang-kadang disebut Saiwa Purana. Siwa Sasana adalah sasana untuk pandita Saiwa. Karena agama Hindu Indonesia memuja Bhatara Siwa, maka Siwa Sasana adalah untuk semua sulinggih Hindu Indonesia (Wijana, 1988). Adapun ajaranajaran yang terkandung pada Lontar Siwa Sasana sebagai berikut :

\section{a. Ajaran Siwaisme}

Lontar Siwa Sasana secara keseluruhan mengandung ajaran Siwa baik itu dari bait 1a16a. Ajaran Siwaisme merupakan salah satu madzab Hindu, asal usulnya tidak banyak kita kenal namun dalam sejarah penyebaran agama Hindu, Siwaisme mempunyai pengaruh dan peranan yang amat penting dalam tata kehidupan agama hindu, terutama setelah siwaisme berkembang menjadi ajaran tantra.

Garis besar ajaran siwa, disamping aspek sosial dan hukum, pada dasarnya sistem kepercayaan siwa berkisar pada tiga hal bila hendak memahaminya untuk lebih mendekatinya lagi, yaitu : yajna (ritual) atau karma, yoga, sadhana. Pemujaan dalam madzab siwa dikenal ada empat macamnya. Keempat macam itu masing-masingnya antara lain :

1) Brahma-bhawa, pemujaan ini bersifat filosofis teologis, dimana pemujaannya cukup mendalami dan mengamalkan pengertian jawatman dan paratman sebagai Brahman.

2) Dhyyana-bhawa, dalam sistem ini pemujaan melalui ajaran yoga dimana penempatan dewata (ista dewata) terus menerus dalam hati melalui yoga Samadhi.

3) Puja-bhawa, yaitu bentuk yang lebih rendah dan paling umum dimana pemujaan dikembangkan atas dasar dan konsep dasar yang dibedakan yaitu antara Tuhan yang dipuja dengan manusia pemujaannya. Dalam pelaksanaan dibedakan antara bentuk internal (dalam) dan dalam bentuk eksternal (luar) unsur terpenting dalam sistem ini adalah adanya japa dan stawa saja untuk bentuk internal. Sedangkan dalam bentuk eksternal masing diperlukan adanya pratima (arca-arca) atau yantra (simbol). (Wijana, 1988)

Pokok-pokok ajaran siwa yang terdapat dalam Lontar Siwa Sasana sebagai berikut: 1b. Nihan Sanghyang Siwa Sasana kayatnakna, de sang watek sadhaka makabehan, sahananira para dhangacaryya saiwa paksa, lwir nira, saiwa siddhanta, wesnawa, pasupata, lepaka, canaka, ratnahara, sambu, nahan lwir nira sang sadhaka saiwa paksa, pramuka sira dhangacarya wrddha pandita, sri guru pata, dhangupadhyaya pita maha, prapita maha, bhagawanta, nahan lwir nira kabeh, yatika kapwa kumayatnaka mrihakmitana sanghyang 
agama siwa sasana, maka don karaksaning kathujangganira, mwang kawinayanira, pagehaning karmmanira, sela nira, mwang kasudharmanira, nguniweh teguhaning tapa brata nira, ri tan hananing wimarga hamanasara sakeng sanghyang kathujanggan, nahan hetu sanghyang agama siwa sasana winakta de sang purwwacaryya wrddha pinandita, ndan lwira sang sadhaka dhangacaryya sang yogya pinaka pagurwan, mwang tan yukti pina Terjemahan :

Inilah Siwa Sasana yang harus diperhatikan para sadhaka, semua guru besar madzab Siwa, seperti, Siwasiddhanta, Wesnawa, Pasupata, Lepaka, Ratnahara, Sambhu. Begitulah jenisnya para sadhaka Siwa paksa, teristimewa bagi para dhang acarya, pandita agung, Sri gurupata, dhang upadhyaya, pita maha, prapita maha, dan bhagawanta, demikian banyaknya. Semua mereka itu harus memperhatikan, menjaga, mempertahankan peraturan agama Siwa, sebagai tujuan untuk menegakkan keserjanaan serta pedoman hidupnya dalam menegakkan kewajiban, kesusilaan, serta dharmanya, begitu pula untuk menegakkan tapa bratanya, agar jangan menyimpang dan nyasar dari hukum keguruan. Itulah sebabnya peraturan agama Siwa yang mulia diutamakan oleh dhang acarya, pendeta agung yang terdahulu (Wijana, 1988).

2a. Ka guru, ya ta cinaritan kramanira rumuhun, nihan lwir nira : sajjanah, wrddha wehaso, sastrajjah, wedaparaggah, dharmajjah, sila sampanah, jitendriyah, drdha bratah.

Nihan lwira sang sadhakanung yoga dhangguru upadhyaya dening loka, acarya wrddha pandita, wrddha ring wayah tuwi, acarya prajja sabdikawaruh mangaji wala widya, mwang tarkka wyakaranadi, acarya weda paraga, wruh ringangga pangupangganyaning Sang hyang catur weda, wru ring kaswadayan sanghyang sruti smerti, acarya stiti gumawe dharma sadhana, sakti ring kagawayaning yaca dana kirtti, acaryya, suddha sila, apageh manutta sadu winayan, pawitra sulaksana kuneng, acarya jitendriya, tyaga kacakta ring bhoga wisaya, acaryya sudhira dharaka teguh ring tapa brata, nahan lwir nira sang sadhu wenang gawayen dhanguapdhyaya, nga dhanga.

Terjemahan :

Adapun sadhka dhang acarya yang patut dijadikan tempat berguru dan yang tidak benar dijadikan guru, yang hendak diceriterakan keadaannya terlebih dahulu. Inilah para sadhaka yang patut dijadikan guru upadhyaya oleh dunia, acarya pandita yang senior, termasuk senior dalam usia. Acarya bijaksana yang paham ilmuy suara, mendalami ilmu agamanya, kuat dalam ilmu pengetahuan serta ilmu 
dialektika, terutama ilmu tata bahasa acarya yang ahli weda, mengarti tentang angga dan pembagian Catur Weda. Mengetahui membaca Sruti maupun Smrti. Acarya yang teguhh melaksanakan dharma sadhana, kuat dalam berbuat jasa dan amal kebajikan, acarya yang suci tingkah lakunya, teguh berpegang pada pedoman kebijaksanaan, bersih dan susila. Acarya yang telah menundukan indria, waspada dan tidak diperbudak oleh segala macam makanan dan kenikmatan dunia. Acarya yang perkasa, taat dan teguh dalam tapa-brata. Demikian sifat orang bijaksana sejati, yang pantas dijadikan guru besar kerohanian (Wijana, 1988).

Dalam kutipan sasana bait 1b-2a diatas dijelaskan bahwa bagi seorang sadhaka (orang ahli, pengikut) mereka harus memperhatikan, menjaga dan mempertahankan peraturan-peraturan agama Siwa. Dalam Siwa Sasana penggunaan kata-kata sadhaka dang upadhyaya sering benar, kadang-kadang berselang-seling. Semuanya menunjuk pada seseorang yang melaksanakan hidup kerohanian sebagai pandita. Acarya dan Dhang Upadhyaya lebih cenderung berarti seorang pandita guru. Disamping itu ada pandita yang disebut dhang acarya wrddha pandita, sriguru pata, dhang upadhyaya pita maha, prapita maha, dan bhagawanta yang masing-masing berarti pandita guru yang agung, guru yang mulia yang senang membaca, kakek guru, kakek yang agung, dan bhagawan. Perbedaan diantara para pandita tersebut di dalam Siwa Sasana tidak dijelaskan. Kepada mereka itulah Siwa Sasana ini ditujukan untuk dilaksanakan dengan tujuan agar mereka dapat mempertahankan martabatnya sebagai Pandita, dan menegakan dharmanya.Suatu uraian yang panjang dalam lontar ini ialah uraian tentang syarat-syarat seorang acarya yang dapat dijadikan guru dan yang harus dihindari sebagai guru. Seperti yang tertulis dalam Lontar Siwa Sasana bait 2b-4b sebagai berikut :

Bait $2 b \quad$ :

Dhangacaryya krtta diksita, pinaka guru guru, panadhahan sangskara mwang bhasma, wenang sadhakanung wenang dumiksanangaskara sakala janma sadhaka wangsa parampara, kinaryya nimitta wiku, tumut sadhaka saiwa paksa, sang sadhaka mangkana kramanya, sirata wiku maha pawitra wenang sira dhangupadhyaya ngaranira, kuneng sang sadhaka sinangguh pangupadhyaya, pilihana jatinira de sang pudghala, ring sedeng nira hyunira sangskara, hyunira sangskara, ikangacaryya sapatuduh inghulun juga pilihana. Deledelen salah siki gawayen guru, sangksepanya, madumpi-dumpilana juga de yaning sisya mangungsi guru, aywanaku guru tahun sing maha pawitra laksana nira paten guru. 
Aparan kaphalaning manembah ring kadi sira sadhaka, wiku maha pawitra, nyapan tahan kwa linganta. Nihan kottamanya kapawitraning maguru sulaksana. Laksmi duhka sahasrani sangsara

Terjemahan :

Yang disebut acarya krta diksita (pandita guru yang sudah didiksa) ialah gurunya guru, tempat mendapatkan sangaskara (penyucian) dan bhasma (abu suci), sadhaka yang berwenang memberikan diksa sangaskara kepada sesama manusia ialah keturunan sadhaka terus menerus, yang memang disiapkan untuk menjadi wiku, mematuhi dharma sadhaka mazab Saiwa. Sadhaka yang demikian itu, adalah wiku yang maha suci dapat disebut dang upadhyaaya (guru besar). Adapun diteliti keturunannya oleh sang penganut mazab Saiwa ketika ingin mendapatkan sangaskara. Hendaknya acarya yang aku tunjukan (kepadamu) juga dipilih. Perhatikan dengan sungguh-sungguh bila memilih salah seorang untuk menjadi guru. Kesimpulannya, hendaknya sisya ikut berperan dalam usaha mencari guru. Janganlah anakku berguru kepada orang yang tidak suci tingkah lakunya menepati susila guru. Apakah pahalanya menyembah sang sadhaka, wiku yang maha suci. Mungkin demikianlah pertanyaanmu. Inilah keutamaan kesucian berguru kepada guru yang berbudi luhur (Wijana, 1988).

Bait $3 b$ :

Diniksa dening sadhaka, nga, alpa sastra, dusprajja, kurang wiweka, nirwicaksana, pisaningun wruha prakr taning aji kdhikkdhik, ngaya durmmeda wippaaryya, lumud jugul jadha linglung lelengo, mungeng, bingung, kumwa prakrtinya, yeka sadhaka mudha, nga. Acaryya duryyasa, nga, adharma, crol nicca prakrtinya, ambeknya mada moha karana durtta murkka madulur katungka, irsya matsara kimbhuru, marta wada mitya sing wuwusnya, sinahajaring kadusilan, durniti durwinaya, nawimukha ringayu, melik ring kagawayaning yasa, manasir sakeng agama rasa, ninda ring hyang lawan ring brahmana, drohiri mitranya, talpaka ring gurunya, masampaying yayah mwang bibinya, yaapwan hana sira sadhaka kumwa kramanya, yeka sadhaka duryyasa, banda tan yukti gawayen guru desang pudghala, aparan kari dosaning wiku mudha.

Terjemahan :

Boleh jadi orang akan terlanjur dipengaruhi oleh sifat-sifat aib sang guru bila mendatangi seorang guru, memohon agar didiksa oleh seorang sadhaka yang buruk tingkah lakunya, sadhaka yang bodoh, yang tidak banyak mengetahui sastra, 
yang kurang berpengetahuan, yang kurang pertimbangan, yang tidak bijaksana. Lebih-lebih lagi seorang sadhaka yang tahu sedikit-sedikit saja pengertian yang terkandung dalam pengetahuan, sehingga ia bodoh, sering salah, ditambah lagi bebal, acuh tak acuh, linglung, melongo, kaku, bingung. Bila demikian perilakunya maka itu adalah sadhaka bodoh namanya. Acarya duryasa ialah acarya yang tidak melaksanakan dharma, curang, berbudi hina, congkak, mabuk yang menyebabkan ia bersifat lirih, angkara murka serta jahat, iri hati, tampak cemburu, mrsawada yaitu segala kata-katanya tidak apat dipercaya. Serta pula dengan berbudi buruk, tidak memperhatikan tuntunan berbuat sesuatu, memalingkan muka dari yang baik benci pada pekerjaanyang berbentuk yasa, menyimpang dari ajaran agama, menghina Tuhan dan Brahmana, bersikap bermusuhan terhadap teman, menentang guru, menghina ibu dan bapaknya. Bila ada sadhaka yang demikian perilakunya, itulah sadhaka duryasa, Tawan. Tidak benar untuk dijadikan guru oleh seorang calon pandita (Wijana, 1988).

Bait 4a :

duryyasa tan yukti gurwaning rat, dumiksana ring sakala jana mahyun wikwa, nyapan tahan kwa linganta, nihan olanya mpih, katatwanika wwang mudha tan wruh ring nayopadeya mwang parartha mwang tan wenang rumaksa dharmma, wetning wiparyyayayynya, matmahan pati purug, mwanganunggawehayu, niyatatmah dosa, nimittaning manemu dewa dhenda, rapuh ning dewa dhendha, mangdadyaken klesa, nirartha kahenengan ya wekasan, nahan halaning mudha, kunang halaning duryyasa, ikang wwang jenek ring adharmma, duma patapa tuwasnya, mamrddhyaken kwehning klesanya, mwang gongning papanya, amngaken babahaningnaraka loka agyagyan, mapalaywan arep mukti pancagati sangsara, pisaningu mahlya muliha ring kasugatin, yata matangnyan sahana nira padha ngacaryya mon mudha duryyasa laksana, nda tan yukti paten guru de sang pudghala.

Terjemahan :

Bagaimana dosa pandita yang dungu, jahat, bohong, mengaku maha guru dunia akan member diksa umat manusia yang ingin menjadi wiku? Agar mengerti, akan saya katakana padamu, nah inilah ulahnya. Hakekat manusia dungu, tak mengerti tentang ilmu pengajaran, tentang tujuan utama menegakkan dharma. Oleh karena bingungnya maka arahnya tak menentu. Yang melakukan karya mulia, nyatanya mendapat dosa, akhirnya mendapat hukuman Dewa. Sedih akibat kutukan Dewa 
itu, menyebabkan sengsara, miskin, akhirnya kekeringan. Demikian kebodohan itu. Adapun bahaya duryasa itu adalah orang yang gemar pada adharma. Hatinya memuja kutukan, memperbanyak jumlah kejahatannya dan memperbesar jumlah kesengsaraan. Jauh dari berubah kembali menuju kesucian. Itulah sebabnya semua golongan acarya kalau dungu dan jahat tingkah lakunya, pantang dijadikan guru oleh calon pendeta (Wijana, 1988).

Bait $4 b$ :

Sangksepanya sang tlas menget, away sira maguru ring adharma sadhaka duryyaca, basama kelu tibeng yama laya, tuhun tikang sadhaka kadi lingku nguni juga swikaran peten guru, ikang wiku nahan pawitra suddha pandita juga sambahenta, mwang dumiksaha kita.Tlas kojaran sang sadhakanung yogya pagurwana, kuneng getyakna tingkahning krama sang sadhakan sampun dhangupadhyaya caritan kramanya, yan hana sira dhangacaryya, sinambgawa gawayen pagurwana, nda haywa ta sira gya lumkas krtta diksita mon turung nipuna ring kriya mwang turung tasak ri tatwa sanghyang kabhujangan, athawa yan turunganiscaya ri rasa sanghyang siwagama, away siragya lumkas, apayapan tan dadi ring dhangupadhyaya, yanagwala mwang amana manaha amuranya kasiwatwan, kuneng deya nira, prakrtining swa sarira nira waswasen rumuhun, rapwan tan katona ngamung, ndya deyaning

Terjemahan :

Kesimpulannya, bagi orang yang sadar, janganlah engkau berguru kepada sadhaka dungu dan hina, tak dapat tiada akan sampai di yamaloka. Sungguh hanya sadhaka yang saya katakan terdahulu juga mohonkan dipilih untuk menjadi guru. Pandita yang demikian itulah yang bersih, suci lagi bijaksana yang patut kau sujudi dan mendiksaimu. Telah saya katakan sang sadhaka yang pantas untuk tempat berguru. Kini kita ganti dengan tingkah laku sadhaka yang telah bergelar dhang upadhyaya. Kita paparkan keadaannya. Kalau ada dhang acarya yang dicintai akan dijadikan tempat berguru, janganlah ngkau segera melaksanakan pemberian diksa sempurna kalau belum paham dengan pekerjaan dan belum matang tentang ilmu kepanditaan, atau belum mendalam tentang ajaran Siwa. Jangan cepat-cepat melaksanakannya, karena pantang bagi dhang upadhyaya kalau tidak menjamin dan masih memikir-mikirkan yang menjadikan campur aduk kebenaran ajaran Siwa. Karena itu sifat-sifat diri pribadinya dilihat terlebih dahulu agar tidak terlihat ngawur (Wijana, 1988). 
Dalam uraian sasana diatas dapat dijelaskan bahwa syarat-syarat untuk menjadi seorang acarya ini amat berat sehingga sukarlah kita mendapatkan acarya seperti itu. Walaupun demikian syarat-syarat ini mencerminkan acarya yang ideal. Syaratsyarat acarya yang baik dijadikan guru ialah : berkepribadian baik, Sastrawan, Ahli Weda, Menguasai hawa nafsu, Taat melaksanakan brata, Senior dalam umur, Ahli bahasa. Acarya krta diksita yaitu acarya yang menjadi gurunya guru ialah acarya keturunan sadhaka yang memang disiapkan untuk menjadi acarya.

Orang harus menghindari acarya yang tidak baik untuk dijadikan guru. Acarya yang demikian ialah acarya yang : Pengetahuannya rendah, acuh tak acuh, cepat bingung, linglung, kaku, duryasa yaitu bermoral rendah seperti rendah budi, congkak, curang, senang mabuk, licik, angkara murka, iri hati, senang berbohong, benci berbuat jasa, bermusuh pada teman, menghina ibu bapaknya, menghina brahmana dan menghina Tuhan, acarya yang demikian akan terbentur-bentur kesana kemari karena bodohnya sehingga ia akan menanggung hukuman para dewa. Akibat dari semua ini, maka acarya yang demikian itu akan tetap hanyut dalam perbuatan yang melawan dharma sehingga pintu neraka terbuka lebar-lebar untuknya.

Bila dikaitkan dengan teori konvergensi, sebagai kesimpulan dapat dikatakan perkembangan manusia kurang lebih ditentukan oleh pembawaan yang turun temurun, serta aktifitas atau penentuan manusia sendiri yang dilakukan dengan bebas di bawah pengaruh faktor-faktor lingkungan tertentu sehingga berkembang menjadi sifat-sifat. Dalam Lontar Siwa Sasana, syarat untuk menjadi seorang sadhaka atau dang acarya dipengaruhi oleh factor keturunan dimana hanya kaum brahmanalah yang boleh melaksanakan sasana tersebut selain itu factor lingkungan juga sangat mempengaruhi, dimana untuk menjadi seorang pandita, hendaknya calon sadhaka harus mendapatkan guru yang tepat serta lingkungan yang mendukung agar sasana yang mereka terapkan dapat berjalan dengan baik. Hal ini sudah sesuai dengan teori konvergensi dimana dalam teori tersebut dijelaskan bahwa pembawaan turun temurun serta aktifitasnya dan faktor lingkungan dapat memberikan sifat-sifat bagi calon individu itu sendiri.

\section{b. Ajaran Tri Kaya Parisudha}

Tri kaya parisudha berasal dari tiga kata yaitu: Tri yang berarti tiga, Kaya yang berarti aktivitas, dan parisudha yang berarti baik/suci. Jadi Tri Kaya Parisudha diartikan tiga aktivitas yang suci/baik. Sebagai umat manusia yang merupakan mahluk termulia, 
hendaknya kita menjalankan tiga aktivitas suci tersebut sehingga kemuliaan kita sebagai manusia tetap terjaga. Selain itu, dengan melakukan tiga aktivitas tersebut diharapkan sikap saling menghargai antar sesama, perdamaian, kerukunan, kebahagiaan, dan segala hal yang baik akan segera terwujud. Dalam Lontar Siwa Sasana dijelaskan mengenai ajaran Tri Kaya Parisudha yang terdapat dalam kutipan sasana pada bait 5a-6a sebagai berikut:

Bait 5a :

Kayika wacikaccewa manasikas tratiyaka, cubha karma niyowyantu trikayamiti kawyate. Trikaya, nga., kaya wwang manah kaya, carira wak, nga., cabda, mana, nga., ambek, ika ta katiga pinasangaken manutang dharma karyya de sang pandita, kapwadine maka bhummya chuba, karma, wyaktinya dharma nika yaya sinangguh kayika.

Terjemahan :

Kayika wacikaccewa manasikas tratiyaka, cubha karma niyowyantu trikayamiti kawyate. Trikaya berarti kaya, wak manah. Kaya adalah kegiatan tubuh. Wak berarti suara. Manah berarti pikiran. Ketiganya itulah diatur oleh sang pandita agar mengikuti ajaran dharma, didesak sebagai dasar perbuatan luhur. Sesungguhnya perbuatan yang benar itulah yang disebut kayika. (Wijana, 1988).

Bait $5 b$ :

Dharmaning wak ya sinangguh wacika. Dharmaning manah ya sinangguh manacika, ika ta kapwa tlas siniddhikara maprawrttya rahayu, maka bhumi dharma sadana, ya kayika wacika manacika, nga. Ri pageh nika katiga, yeka sinangguhan trikaya paramartha, nga. Ling sang pandita, ndyanung ta karih de sang sadhaka rumegepa sanghyang trikaya aparan sadananing manuta ring dharmanya, nyapan tahan ta linga sang sadhaka, Om nihan mpih kagegyenira, unyangulaha sangh sadhaka mon sampun dang upadhyaya, sarwa kriyodyuta, protsaha ta sira mangatya gonga pakaryya yadnya puja, japa mangarccaneng bhatara satata, lota mangabyasa castra mwang amarahana mangaji magawaya yaca mwang kirrti, byetswagata ring sadhaka tumuy, nitya saweha dhana sadhyana yoga sa

Terjemahan :

Berkata yang benar itulah yang disebut wacika. Berpikir yang benar itulah disebut manacika. Itulah semua yang disucikan agar mempunyai sifat-sifat baik sebagai dasar dan alat menuju dharma. Itulah yang disebut kayika, wacika dan manacika setelah kuat ketiganya itu maka dinamai tiga kegiatan yang maha utama. Demikian ujar sang pandita. Bagaimanakah cara sang sadhaka memusatkan trikaya yang 
luhur itu, apakah sarananya yang cocok dengan dharmanya, agar diketahui apa kata sang sadhaka. Om, inilah yang patut dipegang teguh, selalu dilaksanakan oleh sadhaka sejak dahulu, bila telah menjadi dhang upadyaya. Semua gagasan, pekerjaan, berusaha keras dengan tekun ia melakukan semua kewajibannya. Ia selalu meningkatkan berbuat bakti dan pengorbanan, memanjatkan doa kepada Bhatara, tekun mendalami sastra agama dan mengajarkan ilmu, berbuat jasa dan kebajikan. Sopan dan hormat kepada sadhaka yang dating bertamu. Selalu member sedekah. Senja hari melakukan yoga Samadhi, mengheningkan cipta. Banyak melakukan doa memuja Siwa selalu. (Wijana, 1988).

Dalam kutipan dua sasana diatas dijelaskan mengenai ajaran Tri Kaya Parisudha dalam Lontar Siwa Sasana, merupakan pegangan Sang Sadhaka (pengikut Siwa Siddhanta) dalam bertingkah laku melalui Trikaya antara lain : Kaya melalui kegiatan tubuh, Wak berarti suara, Manah berarti pikiran. Perbuatan benar itulah yang disebut Kayika, berkata yang benar itulah yang bernama Wacika dan berpikir yang benar itulah yang disebut Manacika, setelah kuat ketiganya itu maka baru bisa disebut tiga kegiatan yang maha utama. Cara mewujudkan tiga yang maha utama itu dengan cara berbakti an membacakan doa kepada Batara, tekun mendalami sastra agama dan mengajarkan ilmu, berbuat jasa dan kebaikan serta melakukan doa memuja Siwa selalu.

\section{Nilai-Nilai Pendidikan Yang Terkandung Dalam Lontar Siwa Sasana}

Sastra yang merupakan perenungan pengarang terhadap permasalahan kehidupan itu sarat dengan nilai yang terpantul dari kultur sosialnya. Dengan demikian sastra merupakan bagian dari sistem nilai budaya yang dimiliki oleh kelompok sosialnya. Dalam buku, kebudayaan, mentalitas dan pembangunan dinyatakan bahwa sistem nilai budaya merupakan suatu rangkaian abstrak yang hidup dalam alam pikiran sebagai warga suatu masyarakat, mengenai apa yang harus dianggap penting dalam hidupnya, (Koentjaraningrat, 1974).

Koentjaraningrat lebih lanjut mengatakan bahwa nilai budaya itu adalah tingkat pertama kebudayaan ideal lanjutan atau adat. Nilai budaya adalah lapisan paling abstrak dan luas ruang lingkupnya. Tingkat ini ide-ide yang mengkonsepsikan hal-hal yang paling bernilai dalam kehidupan masyarakat. Suatu sistem nilai budaya terdiri dari konsep-konsep yang hidup dalam pikiran sebagian besar warga masyarakat 
mengenai hal-hal yang harus mereka anggap bernilai dalam hidupnya. Oleh karena itu,sistem nilai budaya biasanya berfungsi sebagai pedoman tertinggi bagi kelakuan manusia. Sistem kelakuan lain yang tingkatnya lebih kongkret, seperti aturan-aturan khusus, hukum, dan norma-norma semuanya berpedoman kepada system nilai budaya itu (Koentjaraningrat, 1974). Dari uraian diatas penulis akan menguraikan nilai-nilai Pendidikan Agama Hindu yang terkandung dalam Lontar Siwa Sasana. Adapun nilai-nilai Pendidikan Agama Hindu yang terkanding dalam Lontar Siwa Sasana akan dideskripsikan sebagai berikut :

\section{a. Nilai Pendidikan Etika}

Etika adalah refleksi kritis dan rasional mengenai norma-norma yang terwujud dalam perilaku hidup manusia, baik secara pribadi maupun kelompok. Dalam Lontar Siwa Sasana banyak menekankan tentang etika bagaimana menjadi seorang calon sadhaka, syarat menjadi guru (acarya), dan menghindari acarya yang tidak baik untuk dijadikan guru (Sudarsana, 2000).

Nilai pendidikan etika yang terdapat dalam Lontar Siwa Sasana salah satunya adalah nilai ajaran wiweka. Wiweka merupakan suatu ajaran dalam agama Hindu dimana dalam konsep ajaran wiweka ini kita diajarkan untuk mampu membeda-bedakan, menimbang-nimbang dan akhirnya memilih antara mana hal yang baik dan mana hal yang buruk, salah dan benar dan lain sebagainya. Ajaran ini sangat penting untuk dipelajari, dipahami, dan akhirnya diaplikasikan dalam kehidupan seharihari khususnya bagi seorang sadhaka atau acarya (Trisdyani \& Suadnyana, 2019).

Pada Lontar Siwa Sasana, nilai ajaran wiweka banyak menguraikan tentang bagaimana nilai ajaran wiweka seorang sadhaka dari menuntut ilmu sampai dengan sang sadhaka di diksa serta etika mengenai guru yang harus ditauladani oleh sang sadhaka. Adapun pada Lontar Siwa Sasana pokok ajaran wiweka terdapat dalam sasana bait $6 \mathrm{a}-7 \mathrm{~b}$ sebagai berikut :

Bait $6 a$ :

Samadhi samahita, lota magawe siwa smarana nitya kala, nahan ulahanira sang sadhaka dhang upadhyaya, nyang posikaning sabda pajarakna denira, mujarakna kasthawaning dewa mwang brahmana, nguniweh kasthawan sang maharddhika wrddha pandita, umucaranakna prakrttaning sastra wakya amarahana mangaji, mamicara awala widya mwang amiweka atatwa parijnana mwang agamokta, masari-sartta swabhaya anguccaranakna weda mantra, mwang satya adenirojar, satya ring utpanna, away angujaraken karnna sula ring para, 
away angujaraken wak parusya mwang pisuna mrsawada ring para, ndan away ninda para codya ring kapwa nira sadhaka, mwang kapwanira dhang upadhyaya, away ninda ring kriya mwang gunawan brataning kapwa nira sadhaka, kewalya sira angujarakna satya wakya, mwang katha komala rum manohararjjawa, nahan

Terjemahan :

Demikianlah perilaku sang sadhaka yang telah menjadi dang upadhyaya. Inilah sifat kata-kata yang patut disampaikan olehnya. Yaitu membicarakan tentang pemujaan para dewa dan pujian kepada Brahmana, lebih-lebih lagi pujian kepada pandita senior yang maha bijaksana, menghafalkan perihal ucap-ucap sastra agama, memberikan pelajaran, memperbincangkan segala macam ilmu pengetahuan dan mengkaji pengetahuan filsafat dan ajaran agama, selalu mempelajari dan merapalkan mantra-mantra Weda. Dan ia berkata jujur, setia pada janji dan ia jangan mengeluarkan kata-kata yang menyakitkan telinga orang, jangan berkatakata kasar, dan memfitnah, dan jangan berbohong kepada orang. Dan janganlah menghina orang, jangan mencerca kerja dan sifat brata sesama sadhaka. Hanya kata-kata yang benarlah dan kata-kata yang manis, lemah lembut, menarik hati dan bersahaja yang harus ia ucapkan (Wijana, 1988).

Bait 7a:

Nihan mpih. Anywa gya juga sira lumkas, nanghera juga sakareng yadyastun huwusa menaka pageh sila mwang winaya sang sadhaka, nguwineh samaptaha ring kriya nira tuwi, ndan away juga agya lumkas, ayusya nira herakna, delen wang ning wayah sang sadhaka mwang wrddhaning wayah nira, sangksepanya, ajwa sang sadhaka lumkas krtta diksita, duga mwang tuwuh nira, mwang manwam tuwuhning anakbi nira, basama nanmu wighnaninga lumkas krtta diksita, mon, sira tapwan panitiha ring samangka, kuneng deya niran pangantya, ya sampun wrddha nggawayawa nira sira lumkas, kuneng ingananing dawaning yusa nira, mon sadhaka wet bet ning krta diksita, putra potraka pinangkanggeh nira, yapwan gnep limang puluh tahun, hinganing wayahning tuwuh nira, yogya lumkasa krtta diksita, kuneng yan tan wasaning krtta diksita, ahingan nmang puluh tahun tuwuh nira yogya

Terjemahan :

Jangan juga terburu-buru berbuat, tunggu pula sebentar walaupun perilaku dan disiplin sang sadhaka sudah meyakinkan dan kuat, lebih-lebih pula sudah menyelesaikan tugas-tugasnya, namun walaupun demikian jangan juga terburu- 
buru berbuat.Hendaknya usianya ditunggu, teliti muda umurnya sang sadhaka dan kematangan umurnya. Singkatnya, janganlah sang sadhaka buru-buru didiksa. Perkirakan muda umurnya dan muda umur isterinya. Berbahaya akan mendapatkan bahaya bila melaksanakan pemberian diksa, bila ia belum mengatasi hal-hal yang demikian itu.Adapun tujuan menunggu itu ialah sempurnanya perkembangan jasmaninya untuk mulai bertindak. Adapun batas umurnya, bila ia sadhaka keturunan dari yang sudah didiksa. Bila ia tidak kekerasan dari yang sudah didiksa, maka batas umurnya ialah enam puluh tahun baru ia dapat melaksanakan diksa (Wijana, 1988).

Bait $7 b$ :

Sira lumkasa krtta diksita, away sang ksepanya, away sang sadhaka lumkas krtta diksita, mon lagi yowana, mwang lagi yowana ng anakbi nira, away lumkas krtta diksita mon srti nira turung maren raja swala, yan sampun tlas matuha lakih, lumkas ira dumiksa, nahan hingananing wala niran lumaksana krtta diksita. Ring huwusning prapta wayah sang sadhaka, an genep tuhuning tuwuh nira, irika ta sira lumkas krtta diksita, away sangsaya, parekakna tang pudghala tang sinambhal diksan, manganakna ta sira diksopacara, magawaya dewa grha, kundha, sthandhila, mamarekakna siwopakarana, Iwirnya : bhasma, ganitri, guduha, kundhala, wulang hulu, brahma sutra, ambulungun, pawwahan, camara, argha, tripada sangka, ghanta, jayaghanti, ika ta kabih siwopakarana, nga, anung drwya sang sandhaka

Terjemahan :

Kesimpulannya janganlah sang sadhaka, menjalankan diksa, bila masih muda dan isterinya juga masih muda. Janganlah melaksanakan diksa bila isterinya belum berhenti datang bulan. Bila kedua-duanya sudah cukup tua umurnya, maka ia dapat melaksanakan diksa.Demikianlah batas usia mudanya untuk melaksanakan diksa. Apabila telah tiba usia sang sadhaka dan cukup tua usianya maka pada waktu itulah ia melakukan diksa dan jangan ragu-ragu. Hadapilah yang berpudgala dan alat-alat diksa itu, mengenakan pakaian upacara diksa, membuat Dewagrha, kundha, sthandila, menghadapi alat-alat Siwapakarana, seperti bhasma, ganitri, guduha, kundala, wulang hulu, brahma sutra, ambulungan, pawawahan, camara, argha, tripada, sangka, ghanta, dan jayaghanti (Wijana, 1988). 
Dalam kutipan sasana di atas dijelaskan ajaran nilai pendidikan wiweka mengenai hal yang baik dan buruk untuk menjadi seorang sadhaka. Tidak lancang, tidak memfitnah, berbohong kepada orang dan tidak menghina kepada sesama Sadhaka. Seorang Sadhaka yang taat harus mampu membedakan mana hal yang baik dan mana hal yang buruk, pikiran bersih, suci, tenang, teguh, dan olas asih patut ditegakkan oleh sang sadhaka sebagai pagar budi. Dalam kutipan sasana diatas juga dijelaskan mengenai etika seorang sadhaka sebelum melaksanakan upacara diksa, ia harus paham terhadap peraturan dan tuntunan sang sadhaka. Harus cukup usia dan sempurna, tidak terlalu tua dan tidak terlalu muda, harus diukur dengan usia istrinya. Demikianlah seluruh tatakrama para sadhaka, bagaimana baitnya,inilah yang harus dilaksanakan oleh semua sadhaka dan dang acarya madzab siwa, jangan meremehkan kebujanggaannya, berusahalah sebaik-baiknya menjaga kesadhakaannya, utama menjaga diri dan lingkungan terlebih dahulu, selanjutnya jagalah perbuatan.

\section{b. Nilai Pendidikan Bhakti}

Bhakti artinya cinta kasih. Kata bhakti ini digunakan untuk menunjukkan kasih kepada objek yang lebih tinggi atau lebih luas cakupannya. contoh: kepada orang tua, para leluhur, para dewa, Tuhan Yang Maha Esa. Kata cinta kasih digunakan untuk menunjukkan cinta kepada sesama manusia atau mahluk di bawah manusia : kawan, keluarga, pacar, tetangga, rekan kerja, binatang, tumbuh-tumbuhan, alam samesta ini. Jalan Bhakti Marga: jalan untuk menuju Tuhan Yang Maha Kuasa dengan menggunakan sarana rasa. Orang yang melakukan jalan bhakti disebut Bhakta. (Sudarsana, 2000) menyatakan bahwa bhakti merupakan kasih sayang yang mendalam kepada Tuhan Yang Maha Esa, yang merupakan jalan kepatuhan atau bhakti. Bhaktiyoga disenangi oleh sebagian besar umat manusia. Tuhan merupakan pengejawantahan dari kasih sayang, dan dapat diwujudkan melalui cinta kasih seperti cinta suami kepada istrinya yang mengelora dan menyerap segalanya. Cinta kepada Tuhan harus selalu diusahakan. Mereka yang mencintai Tuhan tak memiliki keinginan ataupun kesedihan. Ia tak pernah membenci mahluk hidup atau benda apapun, dan tak pernah tertarik dengan objek-objek duniawi. Ia merangkul semuanya dalam dekapan tingkat kasih sayangnya. Pada Lontar Siwa Sasana Nilai pendidikan bhakti dapat kita temui dalam bait $5 \mathrm{~b}$ sebagai berikut : 
Dharmaning wak ya sinangguh wacika. Dharmaning manah ya sinangguh manacika, ika ta kapwa tlas siniddhikara maprawrttya rahayu, maka bhumi dharma sadana, ya kayika wacika manacika, nga. Ri pageh nika katiga, yeka sinangguhan trikaya paramartha, nga. Ling sang pandita, ndyanung ta karih de sang sadhaka rumegepa sanghyang trikaya aparan sadananing manuta ring dharmanya, nyapan tahan ta linga sang sadhaka, Om nihan mpih kagegyenira, unyangulaha sangh sadhaka mon sampun dang upadhyaya, sarwa kriyodyuta, protsaha ta sira mangatya gonga pakaryya yadnya puja, japa mangarccaneng bhatara satata, lota mangabyasa castra mwang amarahana mangaji magawaya yaca mwang kirrti, byetswagata ring sadhaka tumuy, nitya saweha dhana sadhyana yoga sa

Terjemahan :

Berkata yang benar itulah yang disebut wacika. Berpikir yang benar itulah disebut manacika. Itulah semua yang disucikan agar mempunyai sifat-sifat baik sebagai dasar dan alat menuju dharma. Itulah yang disebut kayika, wacika dan manacika setelah kuat ketiganya itu maka dinamai tiga kegiatan yang maha utama. Demikian ujar sang pandita. Bagaimanakah cara sang sadhaka memusatkan trikaya yang luhur itu, apakah sarananya yang cocok dengan dharmanya, agar diketahui apa kata sang sadhaka. Om, inilah yang patut dipegang teguh, selalu dilaksanakan oleh sadhaka sejak dahulu, bila telah menjadi dhang upadyaya. Semua gagasan, pekerjaan, berusaha keras dengan tekun ia melakukan semua kewajibannya. Ia selalu meningkatkan berbuat bakti dan pengorbanan, memanjatkan doa kepada Bhatara, tekun mendalami sastra agama dan mengajarkan ilmu, berbuat jasa dan kebajikan. Sopan dan hormat kepada sadhaka yang dating bertamu. Selalu member sedekah. Senja hari melakukan yoga Samadhi, mengheningkan cipta. Banyak melakukan doa memuja Siwa selalu. (Wijana, 1988).

Dalam kutipan sasana diatas dijelaskan nilai pendidikan bhakti seorang sadhaka yang diwujudkan dalam ajaran trikaya, yang harus selalu dipegang teguh dan dilaksanakan oleh sang sadhka bila telah menjadi dang upadhyaya atau acarya. Agar semua hal itu berhasil semua gagasan, pekerjaan harus dilakukan dengan usaha yang keras dan selalu meningkatkan bhakti dan memanjatkan doa selalu kepada bhatara. Dan banyak melakukan doa memuja Dewa Siwa, karena semua itu merupakan sebuah sujud bhakti seorang bhakta dalam ajaran siwaisme. 


\section{Kesimpulan}

Berdasarkan penyajian data dan hasil pembahasan penelitian, maka simpulan yang dapat diambil dari karya ilmiah ini adalah Ajaran-ajaran yang terkandung dalam Lontar Siwa Sasana meliputi ajaran siwaisme dan ajaran Tri Kaya Parisudha. Ajaran siwaisme pada Lontar Siwa Sasana secara keseluruhan mengandung ajaran Siwa baik itu dari bait 1a-16a. Ajaran Siwaisme merupakan salah satu madzab Hindu. Ajaran Tri Kaya Parisudha pada Lontar Siwa Sasana terdapat dalam kutipan sasana pada bait 5a-6a. Ajaran Tri Kaya Parisudha dalam Lontar Siwa Sasana, merupakan pegangan Sang Sadhaka (pengikut Siwa Siddhanta) dalam bertingkah laku melalui Trikaya antara lain : Kaya melalui kegiatan tubuh, Wak berarti suara, Manah berarti pikiran.

Nilai-nilai pendidikan yang terkandung pada Lontar Siwa Sasana meliputi nilai pendidikan etika dan nilai pendidikan bhakti, yang pertama nilai pendidikan etika diimplementasikan melalui nilai ajaran wiweka yang merupakan suatu ajaran dalam agama Hindu dimana dalam konsep ajaran wiweka ini kita diajarkan untuk mampu membeda-bedakan mana hal yang baik dan mana hal yang buruk. Yang kedua nilai pendidikan bhakti dimplementasikan melalui ajaran Tri Kaya Parisudha melalui konsep ajaran Tri kaya. Sesuai dengan teori nilai yang digunakan, isi yang terkandung dalam Lontar Siwa Sasana mengandung nilai etika dengan ajaran didalamnya.

\section{Daftar Pustaka}

Kaelan, M. S. (2005). Metode Penelitian Kualitatif tentang Filsafat.

Koentjaraningrat. (1974). Kebudayaan, mentalitet dan pembangunan. Gramedia.

Moleong, L. J. (1991). Metode Penelitian Kualitatif. Jakarta.

Semiawan, C. R. (2010). Metode penelitian kualitatif. Grasindo.

Suadnyana, I. B. P. E. (2020). Ajaran Agama Hindu Dalam Geguritan Kunjarakarna. Genta Hredaya, 3(1).

Suadnyana, I. B. P. E. (2020). IMPLEMENTASI NILAI ETIKA HINDU PADA GEGURITAN NI SUMALA. Bawi Ayah: Jurnal Pendidikan Agama Dan Budaya Hindu, 11(1), 100-116.

Sudarsana, I. B. P. (2000). Ajaran agama Hindu (filsafat yadnya). Denpasar: Yayasan Dharma Acarya.

Trisdyani, N. L. P., \& Eka, I. B. P. E. S. (2019). Etika Hindu Dalam Cerita Tantri Kamandaka. Jñānasiddhânta: Jurnal Teologi Hindu, 1(1). 
Yuniastuti, N. W., \& Suadnyana, I. B. P. E. (2019). MODEL LAYANAN PENDIDIKAN AGAMA HINDU UNTUK ANAK BERKEBUTUHAN KHUSUS PASCA ERUPSI GUNUNG AGUNG DI SLBN KARANGASEM. WIDYANATYA, 1(2), 32-43. 